\begin{tabular}{|c|l|}
\hline Title & $\begin{array}{l}\text { A nalysis of simultaneous occurrence of shallow surface Fermi level pinning and deep depletion in MOS diode with Mg- } \\
\text { ion-implanted GaN before activation annealing }\end{array}$ \\
\hline Author(s) & A kazawa, Masamichi; Kamoshida, Ryo \\
\hline Citation & $\begin{array}{l}\text { Japanese Journal of A pplied Physics (JJAP), 59(9), 096502 } \\
\text { https://doi.org/40.35848/1347-4065/abac41 }\end{array}$ \\
\hline Issue Date & 2020-09-01 \\
\hline Doc URL & http://hdl.handle.net/2115/82587 \\
\hline Rights & ○ 2020 The Japan Society of A pplied Physics \\
\hline Type & article (author version) \\
\hline File Information & JJAP_A kazawa_A nalysis.pdf \\
\hline
\end{tabular}

Instructions for use 


\section{Analysis of simultaneous occurrence of shallow surface Fermi level pinning and deep depletion in MOS diode with Mg-ion-implanted GaN before activation annealing}

Masamichi Akazawa* and Ryo Kamoshida

Research Center for Integrated Quantum Electronics, Hokkaido University, Sapporo 060-0813, Japan

*E-mail: akazawa@rciqe.hokudai.ac.jp

The characteristics of a MOS diode with Mg-ion-implanted $\mathrm{GaN}$ before activation annealing were investigated. $\mathrm{Mg}$ ion implantation onto $\mathrm{n}-\mathrm{GaN}$ with slightly high $\mathrm{Si}$ doping concentration $\left(5 \times 10^{17} \mathrm{~cm}^{-3}\right)$ was performed with a moderate dosage $\left(1.5 \times 10^{12} \mathrm{~cm}^{-2}\right)$. The completed MOS diode showed n-type features. The capacitance-voltage $(C-V)$ and capacitance-frequency $(C-f)$ characteristics of the MOS diode indicated that shallow surface Fermi level pinning and deep depletion occurred simultaneously. By applying the conductance method to the measured $C-f$ characteristics, a discrete level at $0.2-0.3 \mathrm{eV}$ below the conduction band edge was detected. On the basis of the simulation of the high-frequency-limit $C-V$ curve, the detected discrete level distributed in the bulk of n-GaN rather than at the insulator/semiconductor interface, so that it caused surface Fermi level pinning at a relatively shallow energy level and deep depletion owing to its acceptorlike nature simultaneously. 


\section{Introduction}

$\mathrm{GaN}$ is a promising material for constructing high-efficiency power devices ${ }^{1-3)}$ because it has a wide bandgap ${ }^{3)}$, a high breakdown field ${ }^{4}$, a high electron saturation velocity ${ }^{5)}$, a high electron mobility ${ }^{3)}$, and good thermal conductivity ${ }^{3)}$. Since an excellent insulator/GaN interface can be formed without difficulty ${ }^{6-8)}$, a vertical GaN MOS field-effect transistor is one of the candidate power devices for realizing efficient electric power saving. It can also provide two-dimensional electron gas with high mobility at a heterointerface with III-nitride alloys, enabling the construction of a high-electron-mobility transistor as a high-frequency high-power device.

Ion implantation technology is convenient for achieving a selective doping area in a high-power device, when applicable. However, for GaN, the formation of a p-type region by ion implantation has been difficult. Although $\mathrm{Mg}$ ion implantation is the most promising method for achieving p-type conduction, the activation ratio is usually low even if a large activation energy, such as larger than $200 \mathrm{meV}^{9-11)}$, is considered. Recently, however, successful achievements of a p-type region in $\mathrm{GaN}$ by $\mathrm{Mg}$ ion implantation have been reported $^{12-20)}$. The theoretical upper limit of the activation ratio, which is as high as $10 \%$, has been achieved by a particular rapid thermal annealing (RTA), i.e., multicycle RTA, in which the temperature was increased in a fashion of sequential pulses up to $1420{ }^{\circ} \mathrm{C}$ in 2 $\mathrm{MPa}$ of $\mathrm{N}_{2}$ overpressure ${ }^{12-15)}$. Furthermore, an ultrahigh-pressure annealing technique for Mg-ion-implanted GaN has been introduced as an effective method of forming a p-type region ${ }^{19}$. Even by a conventional RTA technique at a temperature of $1230-1250^{\circ} \mathrm{C}$, the successful formation of a p-type region ${ }^{16-18)}$ and a high activation ratio of $2.3 \%$ have been reported for $\mathrm{Mg}$-ion-implanted $\mathrm{GaN}^{20)}$. A common result among these reports is that a high temperature $\left(\geq 1230^{\circ} \mathrm{C}\right)$ is necessary to activate the $\mathrm{Mg}$ atoms as acceptors ${ }^{16,17)}$.

To employ $\mathrm{Mg}$ ion implantation as a reliable technology, defects should be minimized. For this purpose, we should investigate the defects in $\mathrm{GaN}$ generated by $\mathrm{Mg}$ ion implantation. By positron annihilation spectroscopy (PAS), Uedono et al. found that a complex of a Ga vacancy, $V_{\mathrm{Ga}}$, and $\mathrm{N}$ vacancy, $V_{\mathrm{N}}$, is a dominant vacancy-type defect after $\mathrm{Mg}$ ion implantation ${ }^{21,22)}$. By deep-level transient spectroscopy (DLTS), Alfieri et al. reported the annealing behavior of defect levels up to $1000^{\circ} \mathrm{C}^{23)}$. They found deep levels located at $0.2-1.2 \mathrm{eV}$ below the conduction band edge $E_{\mathrm{C}}$. Narita et al. performed 
coimplantation with $\mathrm{Mg}$ and $\mathrm{H}$ ions to enhance the substitution of $\mathrm{Ga}$ by $\mathrm{Mg}$ while suppressing carrier compensation by $V_{\mathrm{N}}$. This approach resulted in the suppression of the forward leakage current and the current dispersion in $\mathrm{p}$-n junction diodes ${ }^{18)}$.

We previously reported that a deep level located at $0.7-0.8 \mathrm{eV}$ below $E_{\mathrm{C}}$ was detected using a MOS diode fabricated on lightly $\left(1.5 \times 10^{11} \mathrm{~cm}^{-2}\right) \mathrm{Mg}$-ion-implanted GaN without high-temperature $\left(>1200^{\circ} \mathrm{C}\right)$ annealing for activating $\mathrm{Mg}$ acceptors ${ }^{24,25)}$. More recently, we found that an increase in Mg-ion dosage led to a change in the dominant defect level that affected the electrical properties of the MOS diodes ${ }^{26)}$. Namely, the dominant defect level in MOS diodes with moderately $\left(1.5 \times 10^{12} \mathrm{~cm}^{-2}\right) \mathrm{Mg}$-ion-implanted GaN before activation annealing was located between $E_{\mathrm{C}}-0.2 \mathrm{eV}$ and $E_{\mathrm{C}}-0.3 \mathrm{eV}^{26)}$. Still, the electrical properties of the fabricated MOS diodes with moderate $\mathrm{Mg}$ ion dosage are not yet fully understood. In particular, the following things were not clarified.

1) Although the dominant defect level was relatively shallow, deep depletion was observed. The reason for this is unclear.

2) The type, i.e., donorlike or acceptorlike, of the dominant defect level is unclear.

It is useful to deepen our understanding of these, not only for ion implantation but also for MOS physics. In this work, the MOS diode with moderately Mg-ion-implanted GaN is further investigated to clarify these unclear things.

\section{Experimental procedure}

Samples were prepared as shown in Fig. 1(a) and as described below. A Si-doped n-GaN layer ( $3 \mu \mathrm{m}$ thick, $n=5 \times 10^{17} \mathrm{~cm}^{-3}$ ) was grown on a free-standing $\mathrm{n}^{+}-\mathrm{GaN}(0001)$ substrate via an $\mathrm{n}^{+}-\mathrm{GaN}$ buffer layer by metalorganic vapor phase epitaxy (MOVPE). $\mathrm{Mg}$ ion implantation was carried out at room temperature with an energy of $50 \mathrm{keV}$, an angle of $7^{\circ}$, and a dosage of $1.5 \times 10^{12} \mathrm{~cm}^{-2}$. The transport of ions in matter (TRIM) simulation under these conditions indicated that the maximum $\mathrm{Mg}$ concentration was estimated to be $\sim 2 \times 10^{17} \mathrm{~cm}^{-3}$ and that the concentrations of $V_{\mathrm{Ga}}$ and $V_{\mathrm{N}}$ were calculated to be much higher as shown in Fig. 1 (b). Although the distribution profiles of complex defects cannot be obtained by this simulation, the result indicates that high-concentration defects are introduced in the near-surface region by $\mathrm{Mg}$ ion implantation. Therefore, the detection of deep levels should be straightforward for the sample prepared here. After ion implantation, 
a 30-nm-thick $\mathrm{Al}_{2} \mathrm{O}_{3}$ layer was deposited by atomic layer deposition (ALD) using trimethylaluminum and $\mathrm{H}_{2} \mathrm{O}$ at a substrate temperature of $300^{\circ} \mathrm{C}$, followed by the metallization of a top electrode of $\mathrm{Ni} / \mathrm{Au}$ to form a MOS structure and a back ohmic contact of $\mathrm{Ti} / \mathrm{Au}$. The completed MOS structure is schematically shown in Fig. 1(c). Finally, postmetallization annealing (PMA) for reducing the interface state density ${ }^{23-25)}$ was carried out at $300^{\circ} \mathrm{C}$ in air. For the completed MOS diodes, capacitance-voltage $(C-V)$ and capacitance-frequency $(C-f)$ measurements were carried out. Then, a simulation for reproducing the $C-V$ curves was performed to obtain information on the defect levels.

\section{Results and discussion}

\section{1 $C-V$ and $C-f$ characteristics}

The high-frequency $C-V$ curves measured in a frequency range from 1 to $5 \mathrm{MHz}$ are plotted in Fig. 2. It can be seen that the $C-V$ curve approaches the flat feature at the high-frequency limit, which means strong pinning of the Fermi level. Overall, the capacitance is much smaller than the oxide capacitance $C_{\text {ox }}$, indicating a deep depletion feature. The plateau capacitance corresponds to the depletion width of approximately 150 $\mathrm{nm}$. If the carrier concentration was not changed from that in the as-grown $\mathrm{GaN}$, this deep depletion cannot be caused by the surface Fermi level pinning in the band gap. Therefore, a bulk defect state that compensates for the Si donors should have been generated in GaN by $\mathrm{Mg}$ ion implantation.

The $C-f$ characteristics measured in a frequency range from $100 \mathrm{~Hz}$ to $5 \mathrm{MHz}$ are shown in Fig. 3. The capacitance converges to the deep depletion capacitance at the high frequency even if a high positive bias voltage is applied, which is further evidence of strong Fermi level pinning that causes a deep depletion. However, the capacitance change occurs in a relatively high frequency range, which indicates that the cause of the observed frequency dispersion is a relatively shallow gap state. Consequently, the MOS diode with Mg-ion-implanted GaN exhibited electric properties with a dual nature.

The electron-emission time constant $\tau$ of an electron trap level can be estimated by ${ }^{23}$, 27, 28)

$$
\tau=\frac{1}{\sigma v_{t h} N_{C}} \exp \left(\frac{E_{C}-E_{T}}{k T}\right)
$$


where $\sigma$ is the capture cross section, $v_{\text {th }}$ is the electron thermal velocity, $N_{\mathrm{C}}$ is the effective density of states at $E_{\mathrm{C}}, E_{\mathrm{T}}$ is the energy of the electron trap level, $k$ is the Boltzmann constant, and $T$ is temperature. According to this equation, $C-f$ characteristics in the frequency range from $100 \mathrm{~Hz}$ to $5 \mathrm{MHz}$ should be affected by the trap level at $0.2-0.5 \mathrm{eV}$ from the conduction band edge.

By applying the conductance method to the measured $C-f$ characteristics, the interface state density $D_{\text {it }}$ distribution was derived as follows. At a certain bias voltage, the frequency-dependent conductance $G_{\mathrm{p}}$ due to the interface states as a function of the measurement frequency $f($ or $\omega=2 \pi f)$ is given by ${ }^{29)}$

$$
\frac{G_{p}}{\omega}=\frac{C_{O X}^{2}\left(G_{m} / \omega\right)}{\left(G_{m} / \omega\right)^{2}+\left(C_{O X}-C_{m}\right)^{2}},
$$

where $G_{\mathrm{m}}$ and $C_{\mathrm{m}}$ are the measured conductance and capacitance, respectively. If the time constant of the interface state is singly determined to be $\tau, G_{\mathrm{p}}$ is related to the frequency-independent capacitance $C_{\text {it }}$ by

$$
\frac{G_{p}}{\omega}=\frac{\omega \tau}{1+\omega^{2} \tau^{2}} C_{i t}
$$

Figure 4(a) shows plots of $G_{\mathrm{p}} / \omega$ for each bias voltage as a function of $f$ by the solid circles, where the solid lines indicate the fitting based on the calculation using Eq. (3). It can be seen that the conductance peaks at $10^{3}-10^{5} \mathrm{~Hz}$ are well fitted by the single-time-constant model expressed by Eq. (3). Once $C_{\text {it }}$ is obtained, $D_{\text {it }}$ is obtained by

$$
D_{i t}=\frac{C_{i t}}{q^{2}}
$$

By applying Eq. (1) to derive energy of interface states in the band gap, the $D_{\text {it }}$ distribution was obtained as shown in Fig. 4(b) where $\sigma=1 \times 10^{-16} \mathrm{~cm}^{2}$ was assumed as a typical value measured by DLTS ${ }^{30)}$. An abrupt increase in $D_{\text {it }}$ can be seen at $E_{\mathrm{C}}-0.27 \mathrm{eV}$, indicating the existence of a discrete level in the band gap. Namely, a discrete level at $0.27 \mathrm{eV}$ was 
detected. According to the disorder-induced gap state (DIGS) model ${ }^{31,32)}$, the $D_{\text {it }}$ distribution should exhibit a U-shaped feature resulting from the incomplete separation of bonding and antibonding states. Even for insulator/III-nitride interfaces, U-shaped $D_{\text {it }}$ distributions have been measured ${ }^{33}$, 34). However, in the case where high-density bulk defects exist in the near-surface region, a discrete level can be observed in the $D_{\text {it }}$ distribution ${ }^{35,36)}$. Therefore, the discrete level in Fig. 4(b) should indicate the existence of a bulk defect level. According to previous reports ${ }^{30,37-39)}$, this discrete level can be assigned to the divacancy $V_{\mathrm{Ga}}-V_{\mathrm{N}}$, even when considering the variation of $\sigma$, as is discussed later.

\subsection{Simulation of $C-V$ curve}

To investigate the properties of the detected discrete level, the $C-V$ curve was simulated using a simulator developed previously ${ }^{40,41)}$. First of all, the possibility that the observed electric properties of the Mg-ion-implanted sample were dominated by the interface states should be examined. Therefore, we assumed that the detected $D_{\text {it }}$ distribution is a part of the U-shaped distribution of the interface states, and that there are no defect levels in the Mg-ion-implanted GaN. The result is shown in Fig. 5 where the solid line in the inset indicates the assumed $D_{\text {it }}$ distribution. Even assuming an abrupt increase in the $D_{\text {it }}$ around $E_{\mathrm{C}}-0.2 \mathrm{eV}$, the plateau with the deep depletion capacitance of the measured $C-V$ curve cannot be reproduced. This is a reasonable result considering that the Fermi level should be pinned at a relatively shallow energy point where the abrupt increase in $D_{\text {it }}$ occurs, resulting in a saturation of the $C-V$ curve at a high capacitance under the positive bias region. Therefore, it is unlikely that the interface states caused the observed deep depletion.

Considering the above, the possibility that the detected discrete level is a bulk defect level should also be examined. For this purpose, a simulation assuming bulk defect levels was carried out. We found that the assumption of distribution profiles as shown in Fig. 6 for an acceptorlike bulk defect level at $E_{\mathrm{C}}-0.27 \mathrm{eV}$ and a donorlike bulk defect level at $E_{\mathrm{C}}$ $-0.07 \mathrm{eV}$ can reproduce the measured $C-V$ curve with a deep-depletion capacitance. The simulation result for the $C-V$ curve is shown in Fig. 7. Fermi level pinning at a deep depletion capacitance is well reproduced by assuming relatively shallow defect levels. We found that the acceptorlike bulk defect level at $E_{\mathrm{C}}-0.27 \mathrm{eV}$ mainly reproduced the plateau of the $C-V$ curve. Since an additional positive charge was needed to adjust the horizontal 
shift to obtain the best fit, a very shallow donorlike level at $E_{\mathrm{C}}-0.07 \mathrm{eV}$ with the profile shown in Fig. 6 was also assumed. The assumption of the very shallow donor level coincides with that in the previous simulation for the $\operatorname{MOS} C-V$ curve of the Mg-ion-implanted GaN with a lower dosage ${ }^{25)}$. This very shallow donor level can be assigned to $V_{\mathrm{N}}{ }^{42-44)}$.

With the same assumption of defect properties as above, band bending is also simulated. Diagrams of the simulated band bending at different bias voltages are illustrated in Fig. 8. The width of the depletion layer, formed by the acceptorlike defect level at $E_{\mathrm{C}}-$ $0.27 \mathrm{eV}$ distributed in the $\mathrm{GaN}$ bulk, did not change at any bias voltage, although the surface potential varied. This is the origin of the wide plateau at a deep depletion capacitance in the $C-V$ curve. Meanwhile, the surface Fermi level was pinned at $E_{\mathrm{C}}-0.27$ $\mathrm{eV}$ even under a high positive bias. This pinning can cause the frequency dispersion resulting in the detection of the discrete level by the conductance method. Consequently, the acceptorlike defect level at $E_{\mathrm{C}}-0.27 \mathrm{eV}$ can cause surface Fermi level pinning at relatively shallow energy level and deep depletion simultaneously.

Note that the acceptorlike nature of the defect level is necessary for causing deep depletion. If a donorlike defect level at $E_{\mathrm{C}}-0.27 \mathrm{eV}$ is assumed as the dominant defect level, the measured plateau with the deep-depletion capacitance cannot be reproduced. Figure 9 shows an example simulation result for the case where a donorlike defect level at $E_{\mathrm{C}}-0.27 \mathrm{eV}$ with the same distribution profile as in Fig. 6 was assumed. Even with changing the defect profile, the measured $C-V$ curve was not reproduced. Therefore, the deep depletion cannot be explained by the donorlike defects. Consequently, the detected discrete level at $E_{\mathrm{C}}-0.27 \mathrm{eV}$ is highly likely the acceptorlike defect level distributed in the Mg-ion-implanted GaN.

\subsection{Discussion on defect assignment}

Since many types of defect are generated by $\mathrm{Mg}$ ion implantation, there must be defect levels other than the detected one. Still, it has been indicated that one dominant defect level can determine the $C-V$ characteristics of the fabricated MOS diode. Although the energy $E_{\mathrm{C}}-0.27 \mathrm{eV}$ of the detected defect level was determined under the assumption of $\sigma=1 \times 10^{-16} \mathrm{~cm}^{2}$, there is the possibility that $\sigma$ takes another value in the range from 
$1 \times 10^{-17}$ to $1 \times 10^{-15} \mathrm{~cm}^{2}$. Considering this, we should conclude that the energy of the detected defect level is $0.2-0.3 \mathrm{eV}$ below $E_{\mathrm{C}}$ on the basis of Eq. (1). From the results of the DLTS study ${ }^{30,37-39)}$, the defect level at $0.2-0.3 \mathrm{eV}$ below $E_{\mathrm{C}}$ can be assigned to $V_{\mathrm{Ga}}-V_{\mathrm{N}}$. On the other hand, the results of the PAS study ${ }^{21,22)}$ on as-implanted GaN with a similar $\mathrm{Mg}$ concentration indicated that $V_{\mathrm{Ga}}-V_{\mathrm{N}}$ is the dominant vacancy-type defect. Therefore, it is highly likely that the detected defect level can be assigned to $V_{\mathrm{Ga}}-V_{\mathrm{N}}$ and that this defect level is dominant in the fabricated MOS diode.

\section{Conclusions}

The characteristics of the MOS diode with Mg-ion-implanted GaN before activation annealing were investigated. $\mathrm{Mg}$ ion implantation onto $\mathrm{n}-\mathrm{GaN}$ with a slightly high Si doping concentration was performed with a moderate dosage. The completed MOS diode showed the n-type feature. The $C-V$ and $C-f$ characteristics of the MOS diode indicated that shallow surface Fermi level pinning and deep depletion occurred simultaneously. By applying the conductance method to the measured $C-f$ characteristics, a discrete level at $0.2-0.3 \mathrm{eV}$ below $E_{\mathrm{C}}$ was detected. On the basis of the simulation of the high-frequency-limit $C-V$ curve, the detected discrete level was found to be acceptorlike and distributed in the bulk of n-GaN rather than at the insulator/semiconductor interface, so it simultaneously caused surface Fermi level pinning at a relatively shallow energy level and deep depletion.

\section{Acknowledgments}

The authors thank Dr. T. Narita of Toyota Central R\&D Labs., Inc. for the MOVPE growth of GaN epitaxial layers. They are also thankful to Dr. K. Nishiguchi, a graduate of Hokkaido University, for providing the computer program for simulating $C-V$ curves. This work was supported by MEXT "Research and development of next-generation semiconductor to realize energy-saving society" Program Grant Number JPJ005357 and by JSPS KAKENHI Grant Number JP16H06421. 


\section{References}

1) T. Kachi, Jpn. J. Appl. Phys. 53, 100210 (2014).

2) H. Amano et al., J. Phys. D, Appl. Phys. 51, 163001 (2018).

3) D. Ueda, in Power GaN Devices, eds. M. Meneghini, G. Meneghesso, and E. Zanoni, (Springer, New York, 2017), Ch. 1.

4) B. J. Baliga, Semicond. Sci. Technol. 28, 074011 (2013).

5) F. Schwierz, Solid-State Electronics 49, 889 (2005).

6) S. Kaneki, J. Ohira, S. Toiya, Z. Yatabe, J. T. Asubar, T. Hashizume, Appl. Phys. Lett. 109, 162104 (2016).

7) T. Hashizume, S. Kaneki, T. Oyobiki, Y. Ando, S. Sasaki, and K. Nishiguchi, Appl. Phys. Express 11, 124102 (2018).

8) T. Yamada, D. Terashima, M. Nozaki, H. Yamada, T. Takahashi, M. Shimizu, A. Yoshigoe, T. Hosoi. T. Shimura, H. Watanabe, Jpn. J. Appl. Phys. 58, SCCD06 (2019).

9) S. Brochen, J. Brault, S. Chenot, A. Dussaigne, M. Leroux, and B. Damilano, Appl. Phys. Lett. 103, 032102 (2013).

10) M. Horita, S. Takashima, R. Tanaka, H. Matsuyama, K. Ueno, M. Edo, T. Takanashi, M. Shimizu, and J. Suda, Jpn. J. Appl. Phys., Part 1 56, 031001 (2017).

11) T. Narita, K. Tomita, Y. Tokuda, T. Kogiso, M. Horita, and T. Kachi, J. Appl. Phys. 124, 215701 (2018).

12) B. N. Feigelson, T. J. Anderson, M. Abraham, J. A. Freitas, J. K. Hite, C. R. Eddy and F. J. Kub, J. Cryst. Growth 350, 21 (2012).

13) T. J. Anderson, B. N. Feigelson, F. J. Kub, M. J. Tadjer, K. D. Hobart, M. A. Mastro, J. K. Hite and C. R. Eddy, Electron. Lett. 50, 197 (2014).

14) J. D. Greenlee, T. J. Anderson, B. N. Feigelson, K. D. Hobart and F. J. Kub, Phys. Status Solidi A 212, 2772 (2015).

15) T. J. Anderson, J. D. Greenlee, B. N. Feigelson, J. K. Hite, K. D. Hobart and F. J. Kub, IEEE Trans. Semicond. Manuf. 29, 343 (2016).

16) K. Nomoto, K. Takahashi, T. Oikawa, H. Ogawa, T. Nishimura, T. Mishima, H. G. Xing and T. Nakamura, ECS Trans. 69, 105 (2015).

17) T. Oikawa, Y. Saijo, S. Kato, T. Mishima and T. Nakamura, Nuclear Instruments and Methods in Physics Research B 365, 168 (2015). 
18) T. Narita, T. Kachi, K. Kataoka and T. Uesugi, Appl. Phys. Exp. 10, 016501 (2017).

19) H. Sakurai, M. Omori, S. Yamada, Y. Furukawa, H. Suzuki, T. Narita, K. Kataoka, M. Horita, M. Bockowski, J. Suda, and T. Kachi, Appl. Phys. Lett. 115, 142104 (2019).

20) T. Niwa, T. Fujii and T. Oka, Appl. Phys. Express 10, 091002 (2017).

21) A. Uedono, S. Takashima, M. Edo, K. Ueno, H. Matsuyama, H. Kudo, H. Naramoto and S. Ishibashi, Phys. Status Solidi B 252, 2794 (2015).

22) A. Uedono, S. Takashima, M. Edo, K. Ueno, H. Matsuyama, W. Egger, T. Koschine, C. Hugenschmidt, M. Dickmann, K. Kojima, S.F. Chichibu and S. Ishibashi, Phys. Status Solidi B 255, 1700521 (2018).

23) G. Alfieri, V.K. Sundaramoorthy and R. Micheletto, J. Appl. Phys. 123, 205303 (2018).

24) M. Akazawa, N. Yokota and K. Uetake, AIP Advances 8, 025310 (2018).

25) M. Akazawa and K. Uetake, Jpn. J. Appl. Phys. 58, SCCB10 (2019).

26) M. Akazawa, R. Kamoshida, S. Murai, T. Narita, M. Omori, J. Suda, and T. Kachi, Phys. Status Solidi B 256, 1900367 (2019).

27) P. Kamyczek, E. Placzek-Popko, E. Zielony and Z. Zytkiewicz, Material Science-Poland 31, 572 (2013).

28) P. Hacke, T. Detchprohm, K. Hiramatsu, N. Sawaki, K. Tadatomo and K. Miyake, J. Appl. Phys. 76, 304 (1994).

29) S. M. Sze and K. K. Ng, Physics of Semiconductor Devices (Wiley, Hoboken, NJ, 2007) 3rd ed., Chap. 4.

30) Y. Tokuda, Y. Matsuoka, H. Ueda, O. Ishigro, N. Soejima and T. Kachi, Superlattice and Microstructures 40, 268 (2006).

31) H. Hasegawa and H. Ohno, J. Vac. Sci. \& Technol. B 4, 1130 (1986).

32) H. Hasegawa and M. Akazawa, Appl. Surf. Sci 254, 8005 (2008).

33) C. Mizue, Y. Hori, M. Miczec and T. Hashizume, Jpn. J. Appl. Phys. 50, 021001 (2011).

34) M. Matys, B. Adamowicz, A. Domanowska, A. Michalewicz, R. Stoklas, M. Akazawa, Z. Yatabe and T. Hashizume, J. Appl. Phys. 120, 225305 (2016).

35) T. Sawada, K. Numata, S. Tohdoh, T. Saitoh and H. Hasegawa, Jpn. J. Appl. Phys. 32, $511(1993)$. 
36) T. Hashizume and R. Nakasaki, Appl. Phys. Lett. 80, 4564 (2002).

37) Z.-Q. Fang, D. C. Look, J. Jasinski, M. Benamara, Z. Liliental-Weber, R. J. Molnar, Appl. Phys. Lett. 78, 332 (2001).

38) Z.-Q. Fang, D. C. Look, X.-L. Wang, J. Han, F. A. Khan, I. Adesida, Appl. Phys. Lett. 82, 1562 (2003).

39) U. Honda, Y. Yamada, Y. Tokuda and K. Shiojima, Jpn. J. Appl. Phys. 51, 04DF04 (2012).

40) K. Nishiguchi, S. Kaneki, S. Ozaki and T. Hashizume, Jpn. J. Appl. Phys. 56, 101001 (2017).

41) S. Yamada, H. Sakurai, M. Omori, Y. Osada, R. Kamimura, T. Oyobiki. K. Nishiguci, T. Hashizume and T. Kachi, presented at Int. Conf. on Materials and Systems for Sustainability 2017 (ICMaSS2017, Nagoya, Japan, Sep. 29 - Oct. 1, 2017).

42) D.C. Look, G.C. Farlow, P.J. Drevinsky, D.F. Bliss and J.R. Sizelove, Appl. Phys. Lett. 83, 3525 (2003).

43) D.C. Look, Z.-Q. Fang and B. Claflin, J. Cryst. Growth 281, 143 (2005).

44) J. L. Lyons and C. G. Van de Walle, NPJ Computational Materials 12, 1 (2017). 


\section{Figure Captions}

Fig. 1. (a) Sequence of sample preparation. (b) TRIM simulation results for concentration of $\mathrm{Mg}, V_{\mathrm{Ga}}$, and $V_{\mathrm{N}}$. (c) Sample structure.

Fig. 2. Measured high-frequency $C-V$ and $G / \omega-V$ characteristics of the MOS diode with Mg-ion-implanted GaN.

Fig. 3. Measured $C-f$ and $G / \omega-f$ characteristics of the MOS diode with Mg-ion-implanted GaN.

Fig. 4. (a) Measured $G_{\mathrm{p}} / \omega-V$ characteristics. (b) Measured $D_{\text {it }}$ distribution.

Fig. 5. Simulation result for $C-V$ characteristics of the MOS diode with Mg-ion-implanted GaN assuming that the measured $D_{\text {it }}$ distribution resulted from interface states (inset).

Fig. 6. Bulk defect level profiles assumed in the simulation.

Fig. 7. Simulation result for $C-V$ characteristics of the MOS diode with $\mathrm{Mg}$-ion-implanted $\mathrm{GaN}$ assuming an acceptor level at $E_{\mathrm{C}}-0.27 \mathrm{eV}$ and a donor level at $E_{\mathrm{C}}-0.07 \mathrm{eV}$ having density profiles shown in Fig. 6.

Fig. 8. Simulation result for band bending of Mg-ion-implanted GaN in a MOS structure assuming an acceptor level at $E_{\mathrm{C}}-0.27 \mathrm{eV}$ and a donor level at $E_{\mathrm{C}}-0.07 \mathrm{eV}$ having density profiles shown in Fig. 7. (a) $V=-5 \mathrm{~V}$, (b) $V=0 \mathrm{~V}$, (c) $V=5 \mathrm{~V}$, and (d) $V=10 \mathrm{~V}$.

Fig. 9. Simulation result for $C-V$ characteristics of the MOS diode with $\mathrm{Mg}$-ion-implanted GaN assuming only a donor level at $E_{\mathrm{C}}-0.27 \mathrm{eV}$ having density profiles shown in Fig. 6 . 
(a)

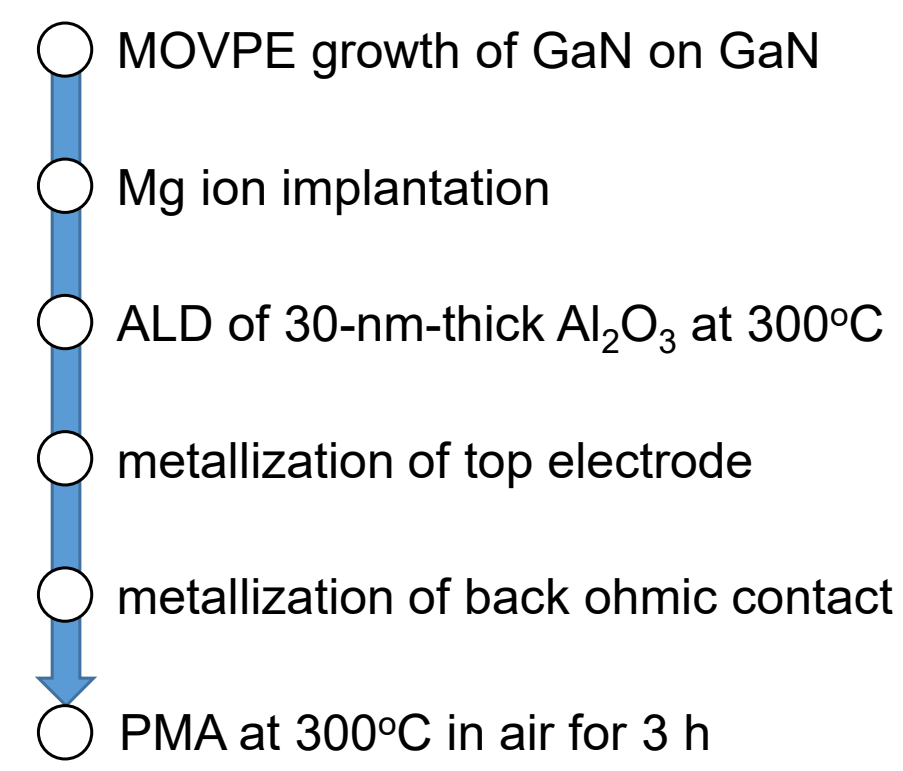

(b)

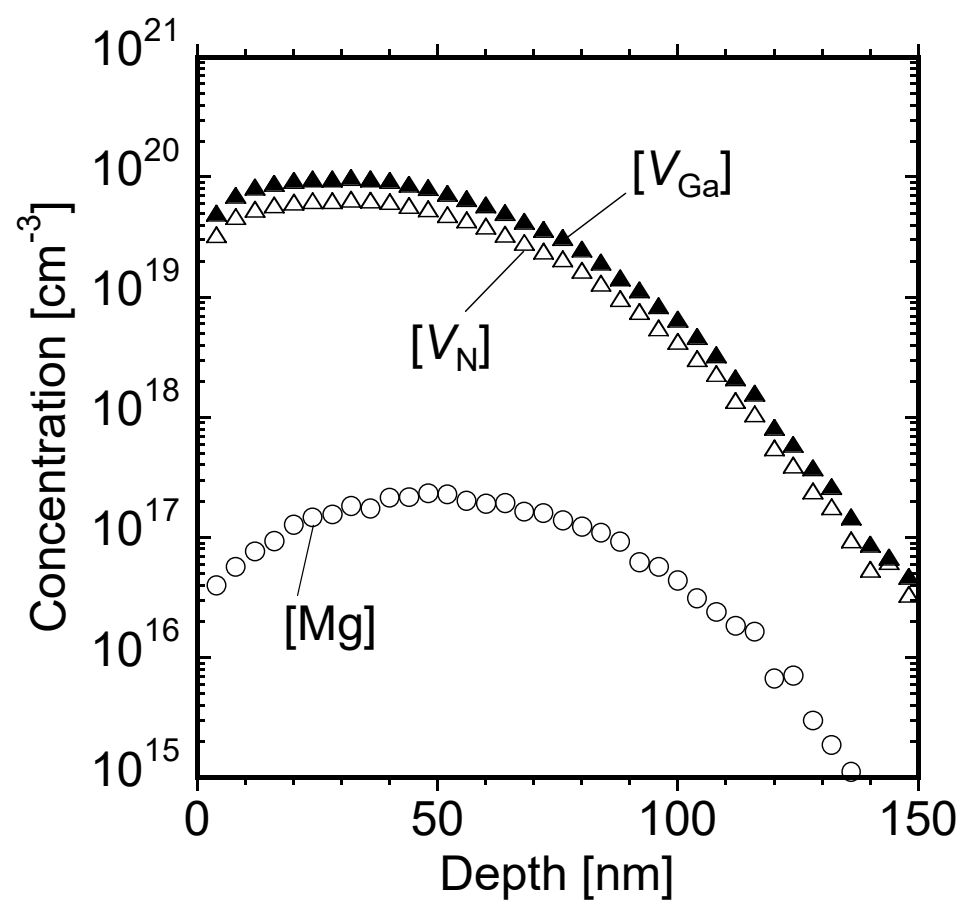

Fig.1. 
(c)

\begin{tabular}{|c|}
\cline { 2 - 2 } \multicolumn{1}{c|}{$\mathrm{Ni} / \mathrm{Au}$} \\
\hline $\mathrm{ALD} \mathrm{Al}{ }_{2} \mathrm{O}_{3}$ \\
\hline $\mathrm{ng}$-GaNplanted GaN \\
\hline $\mathrm{n}^{+}$-GaN substrate \\
\hline ohmic contact \\
\hline
\end{tabular}

Fig. 1 
Fig. 2
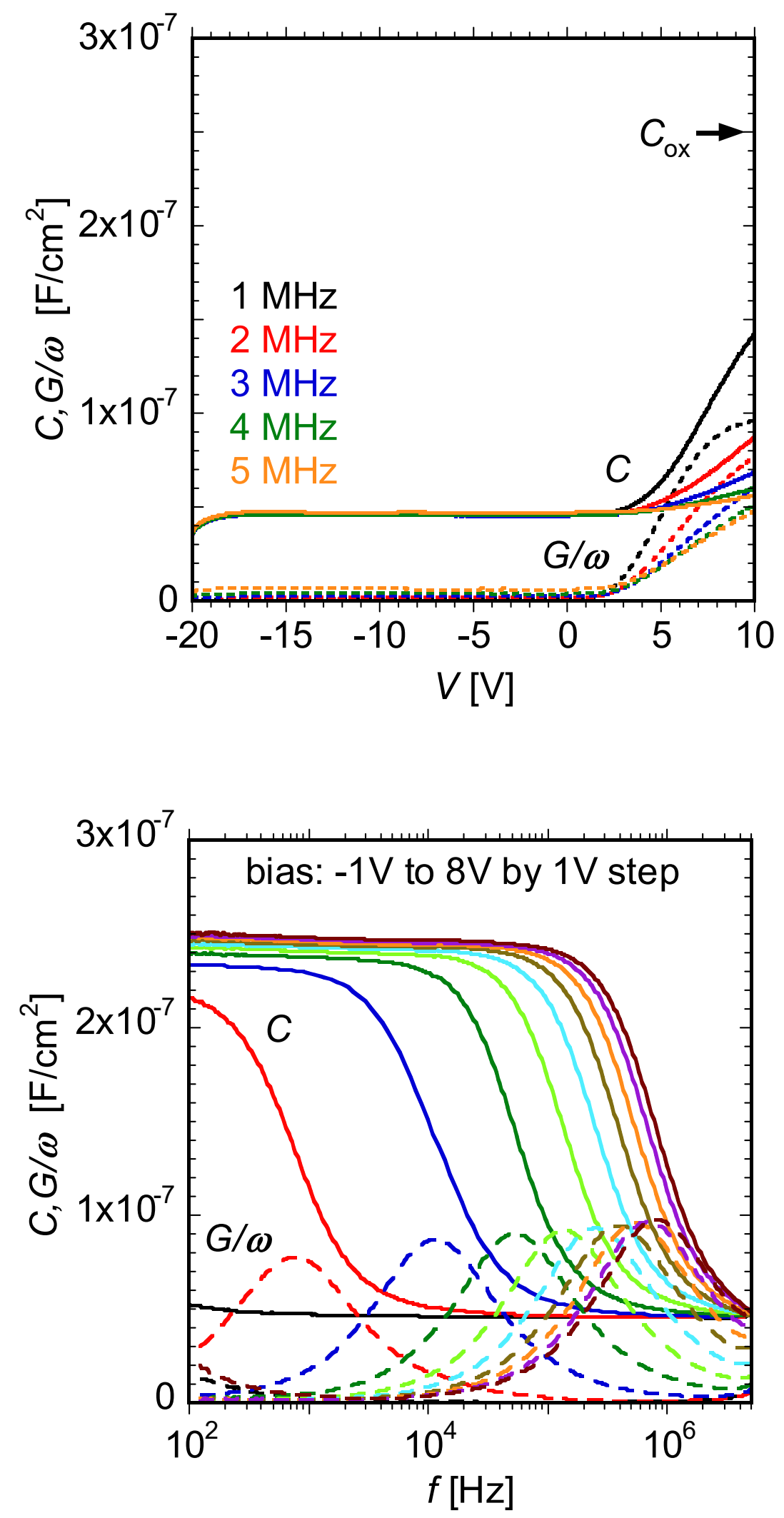

Fig. 3 

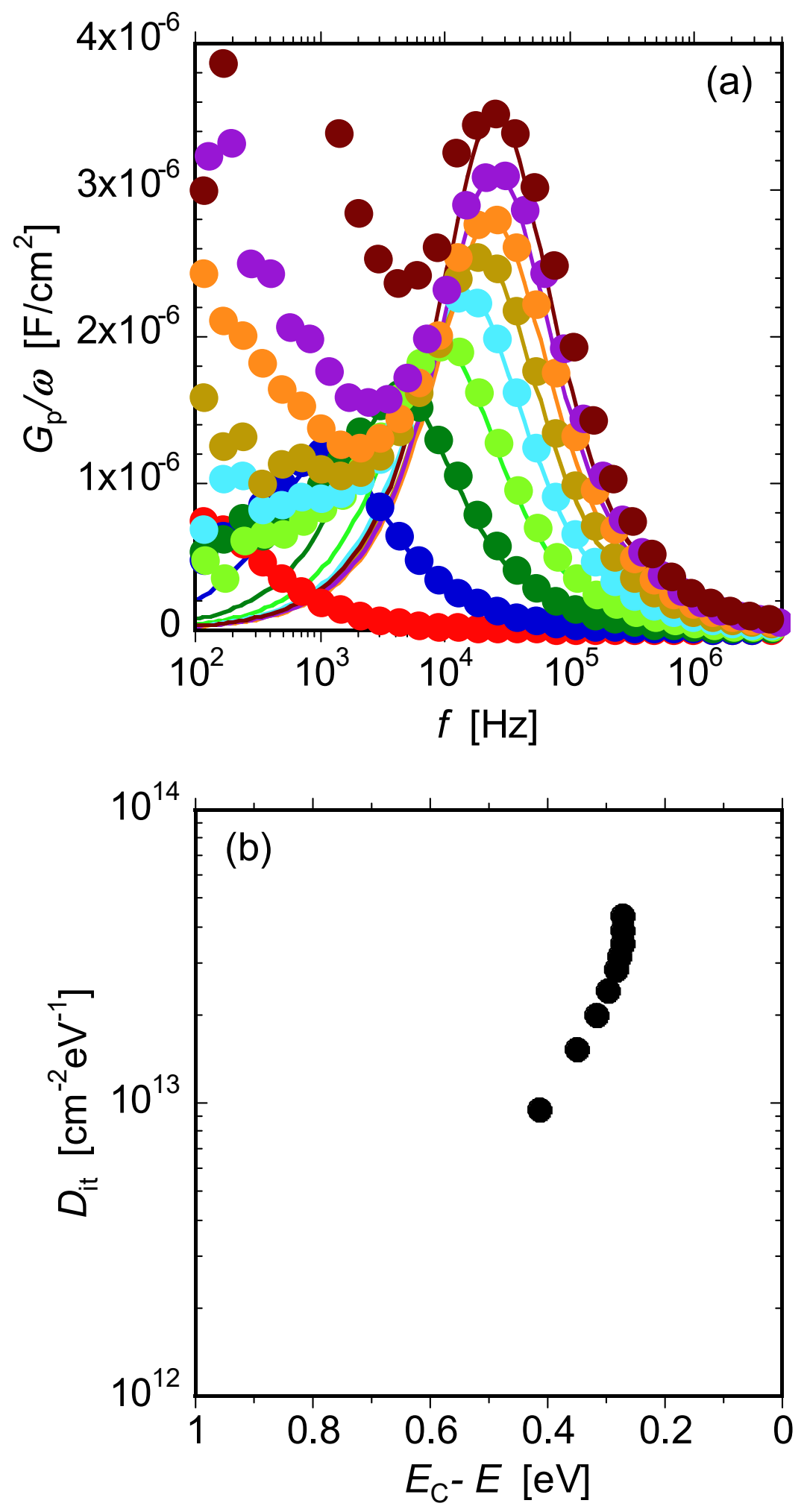

Fig. 4 


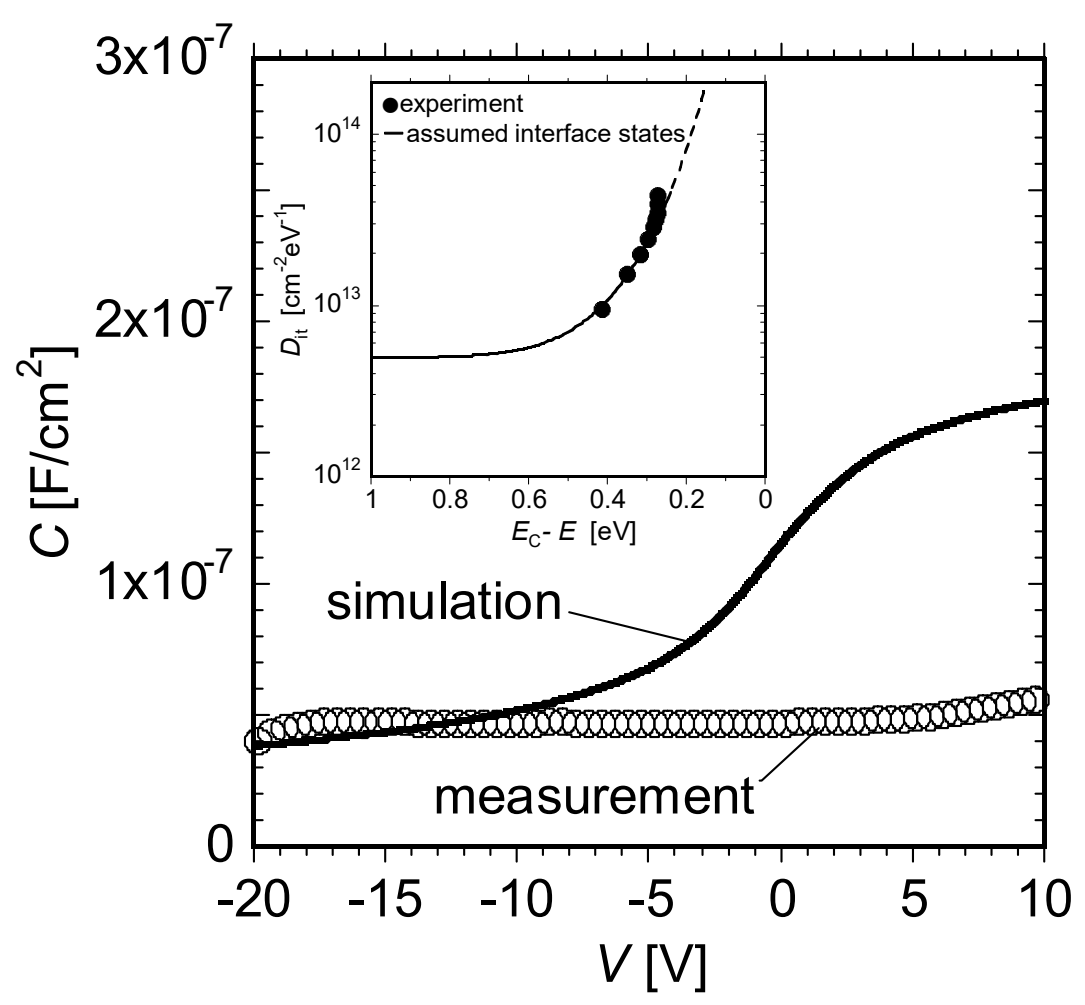

Fig. 5

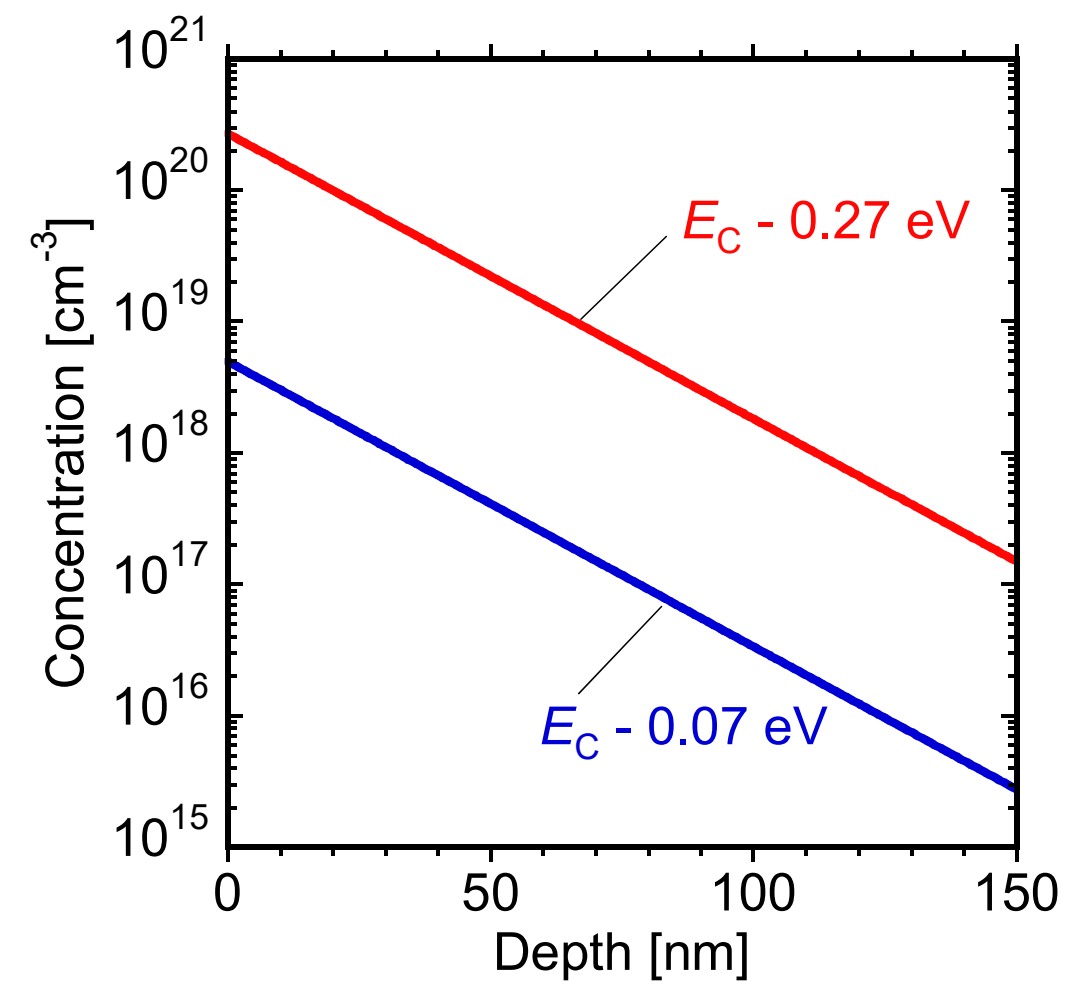

Fig. 6 


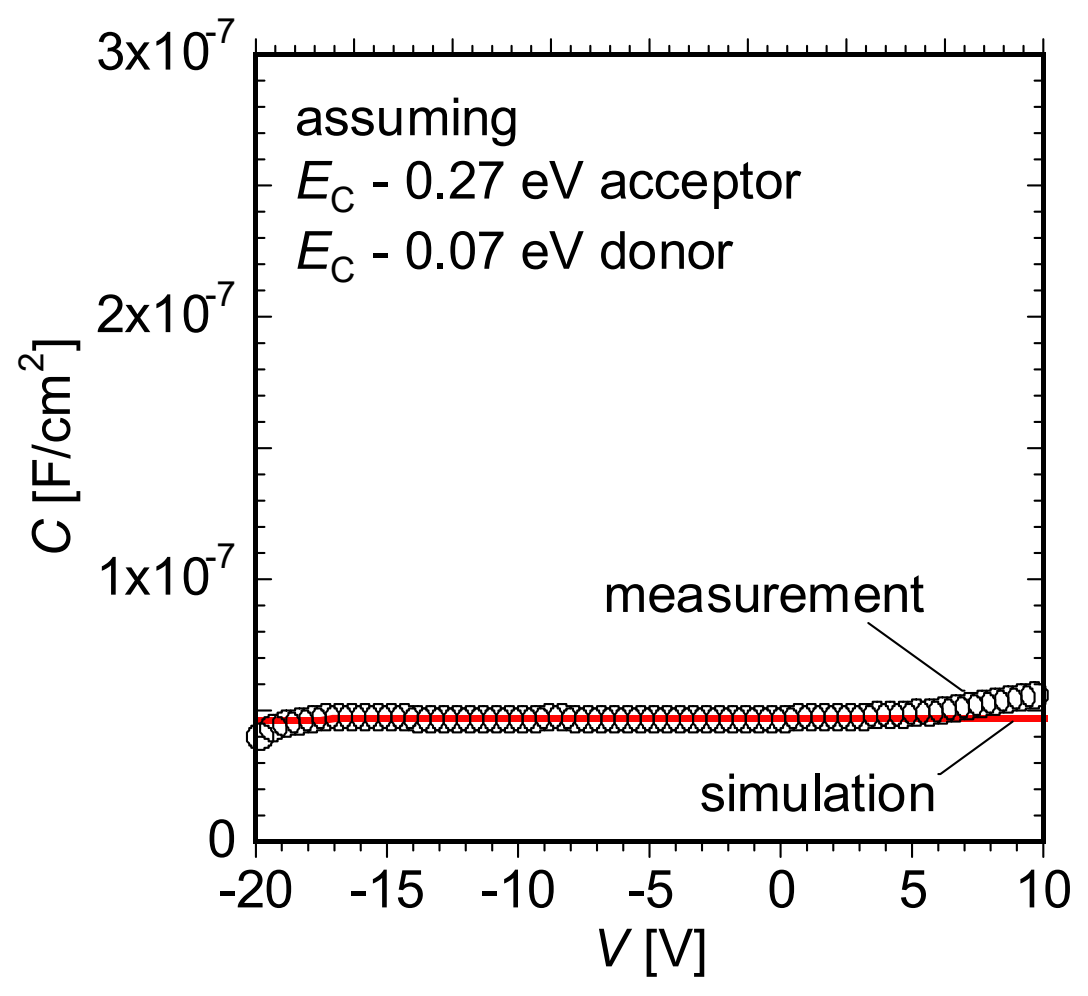

Fig. 7 

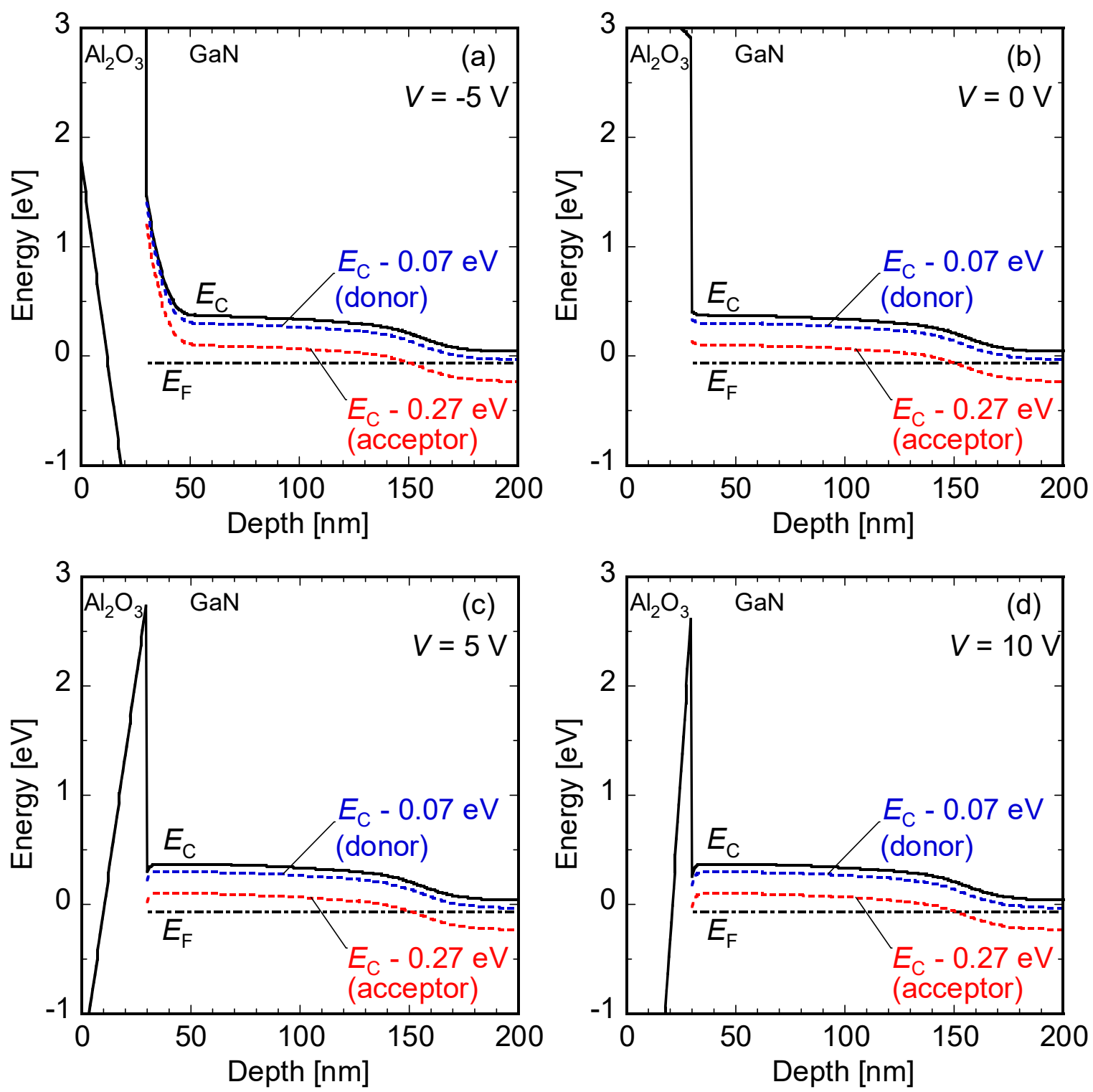

Fig. 8 


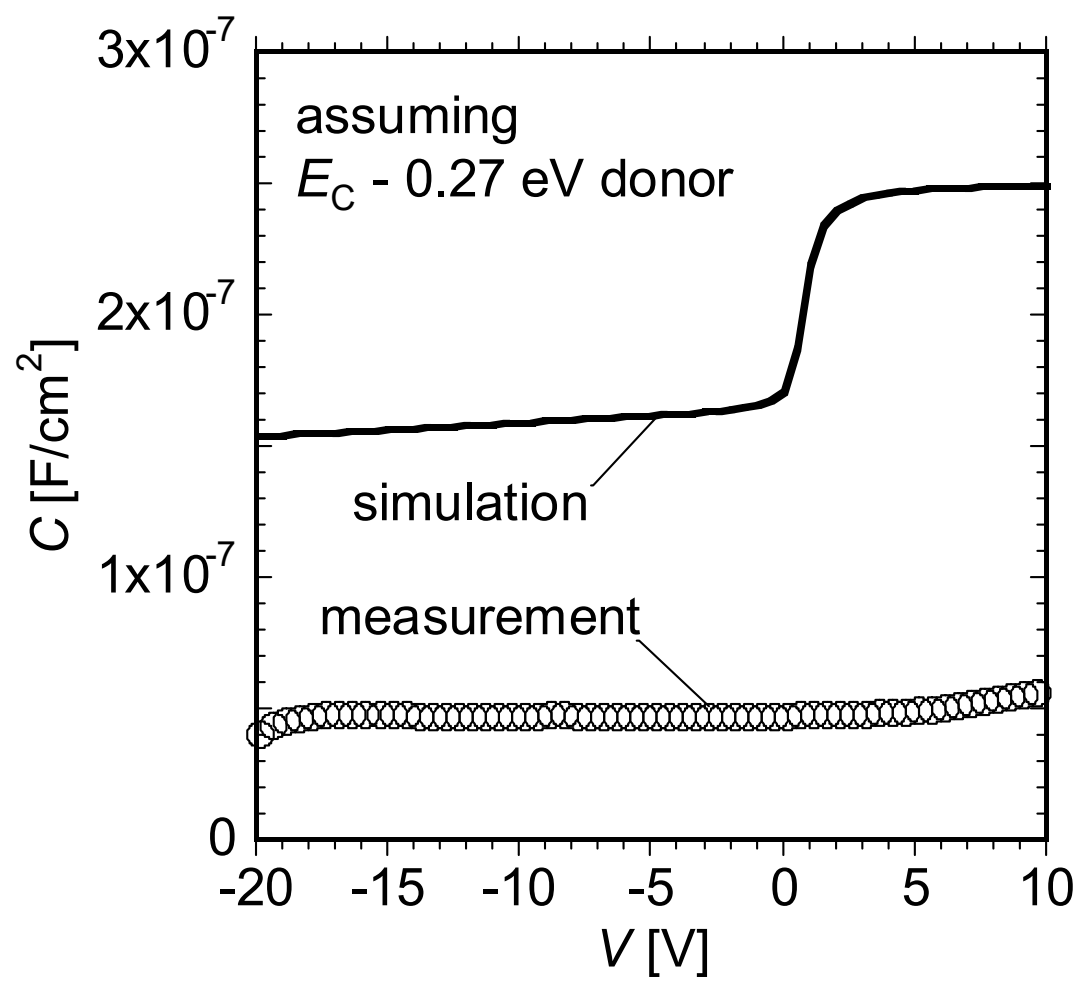

Fig. 9 